
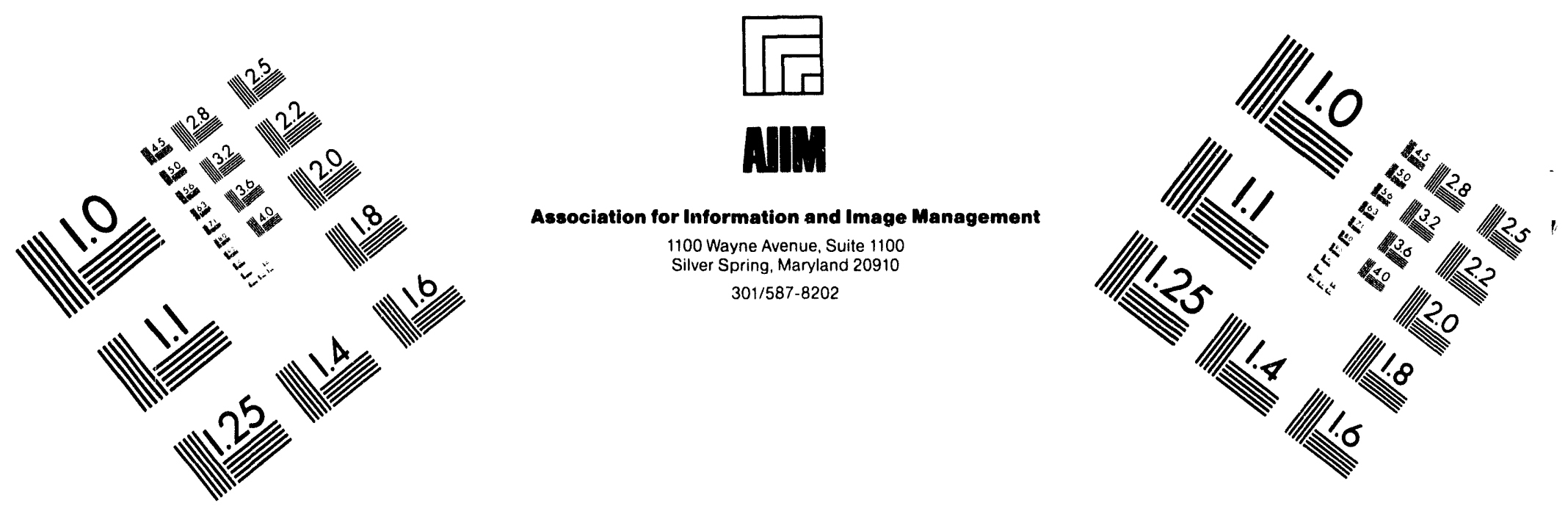

\title{
Centimeter
}

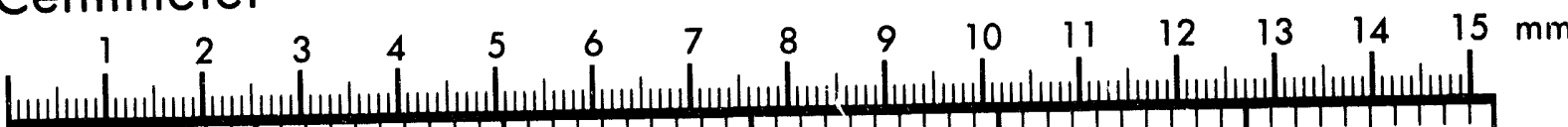

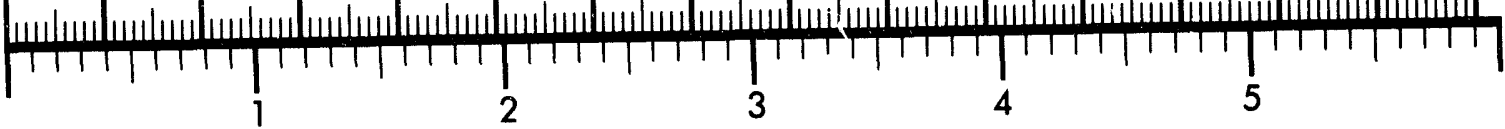
Inches
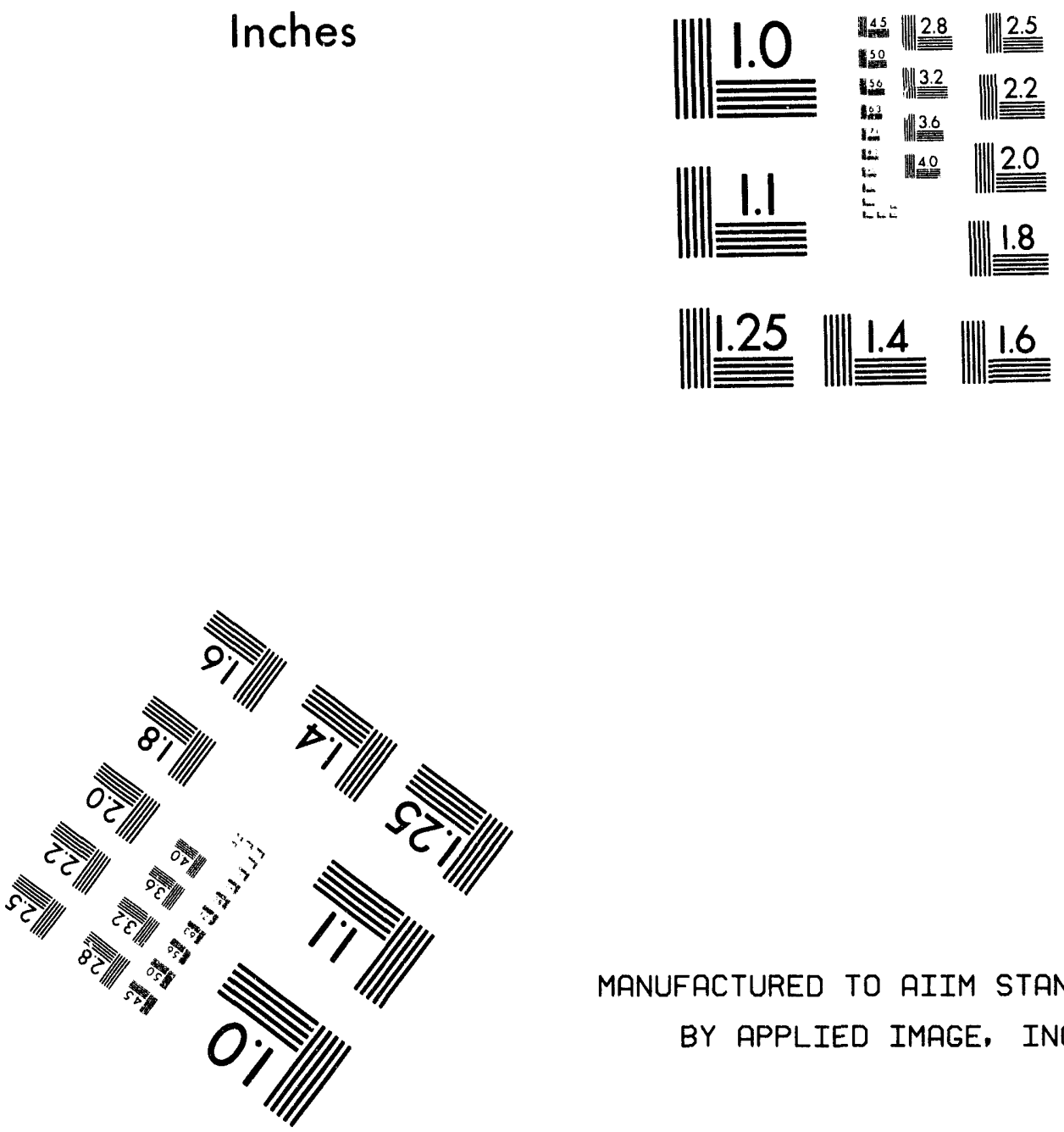

MANUFACTURED TO AIIM STANDARDS BY APPLIED IMAGE, INC.

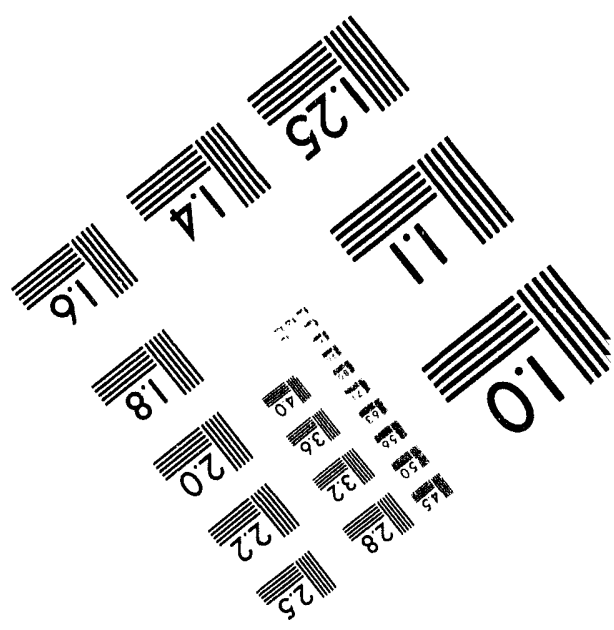



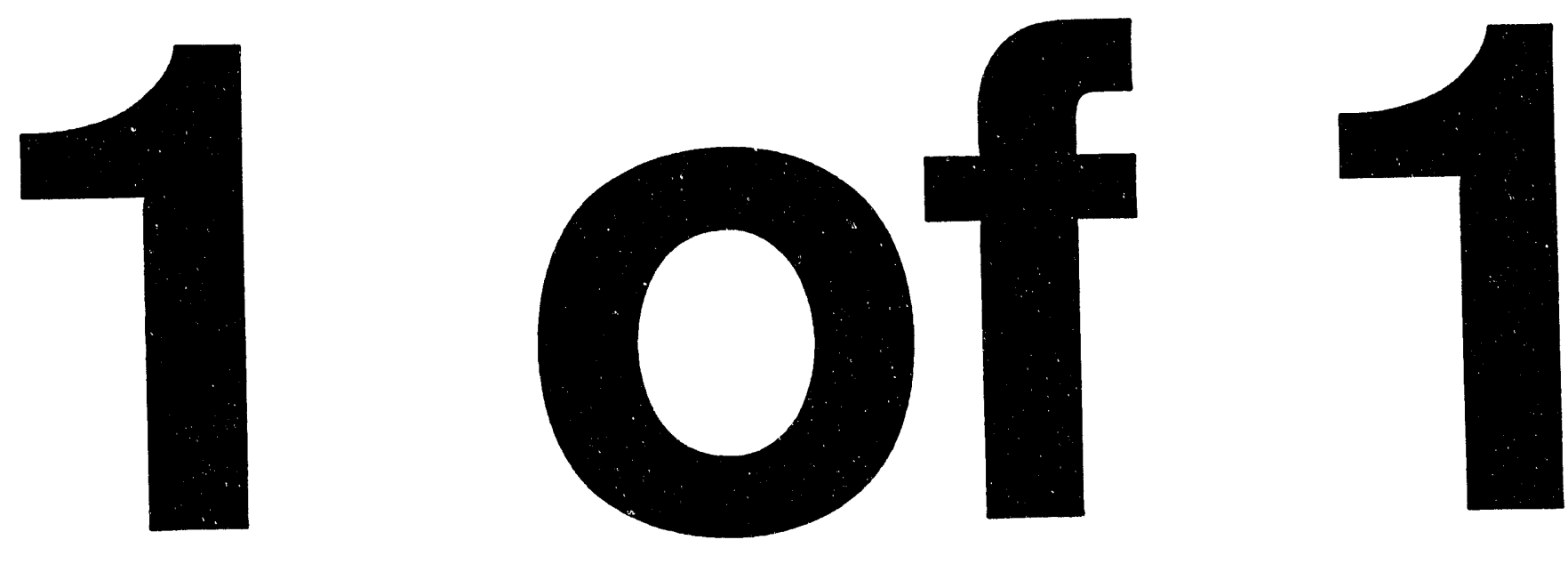


\section{Conf- $940664--15$}

LA-UR- $94-1873$

\section{Title: $\quad$ THE ROLE OF SIDESTREAM RECYCLE IN HYDROGEN ISOTOPE SEPARATION AND COLUMN CASCADE DESIGN}

Author(s):

Submitted to:

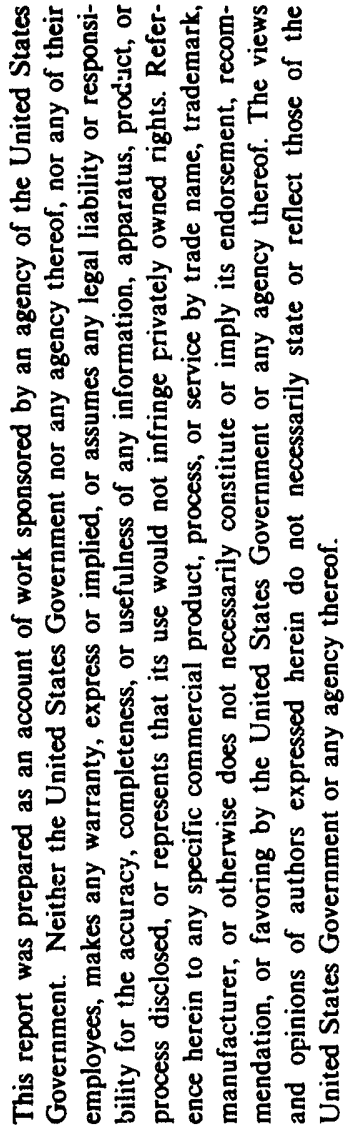

Robert H. Sherman and David J. Taylor

Tritium systems Test Assembly, Los Alamos National Laboratory, MS-C348, P.O. Box 1663, Los Alamos, New Mexico 87545, USA

T. Yamanishi, M. Enoeda, S. Konishi, and K. Okuno Japan Atomic Energy Research Institute Tokai-mura, Ibaraki-ken, Japan

Third International Symposium on Fusion Nuclear Technology

\section{Los Alamos} NATIONAL LABORATORY

Los Alamos National Laboratory, an affirmative action/equal opportunity employer, is operated by the University of California for the U.S. Department of Energy under contract W-7405-ENG-36. By acceptance of this article, the publisher recognizes that the U.S. Government retains a nonexclusive, royalty-free license to publish or reproduce the published form of this contribution, or to allow others to do so, for U.S. Government purposes. The Los Alamos National Laboratory requests that the publisher identify this article as work performed under the auspices of the U.S. Department of Energy. 


\title{
THE ROLE OF SIDESTREAM RECYCLE IN HYDROGEN ISOTOPE SEPARATION AND COLUMN CASCADE DESIGN
}

\author{
Robert H. Sherman and David J. Taylor \\ Tritium Systems Test Assembly, Los Alamos National Laboratory \\ MS-C348, P.O. Box 1663, Los Alamos, New Mexico 87545, USA \\ and
T. Yamanishi, M. Enoeda, S. Konishi, and K. Okuno
Japan Atomic Energy Research Institute \\ Tokai-mura, Ibaraki-ken, Japan
}

\begin{abstract}
Sidestream recycle combined with sidestream equilibration is important in hydrogen isotopic distillation processes because it offers a means to reduce the number of columns required for the extraction of pure homonuclear species. This directly implies simpler systems, reduced control problems, and reduced material inventories. Measurements were recently completed for a single distillation column using feed compositions ( $\mathbf{5 0 - 5 0} \mathrm{D}-\mathrm{T})$ and product flows similar to those expected in an ITER type device with recycle of an equilibrated sidestream withdrawn from the column. Dynamic studies were conducted with flowrates changing as might be expected for typical Tokamak operations. These experimental results are compared with computer simulations of the dynamic process. The impact of these sidestream recycle studies on the design of isotope separation systems is discussed, especially with respect to column design, tritium inventory, dynamic performance, stability, and system control.
\end{abstract}

\section{INTRODUCTION}

Distillation is often the most efficient means to separate the components of a mixture. A two-component mixture can be separated into product streams of high purity using a single distillation column. However, separation of hydrogen isotopes (e.g. $\mathrm{D}_{2} / \mathrm{T}_{2}$ ) by distillation is complicated by the existence of stable mixed-isotope molecules (molecular DT), so that a sequence of distillation columns and equilibrators is generally required when the feed tritium is primarily DT. The technique of sidestream recycle with sidestream equilibration can substantially enhance the purity of at least one of the product streams from a single-column isotope separation system (ISS) by strategically withdrawing a sidestream containing relatively high concentrations of the mixedisotope molecule, which is broken up by equilibration. In a previous paper[1] data was presented for a single-column distillation experiment on an equilibrated mixture of essentially $\mathrm{H}_{2}$ and $\mathrm{D}_{2}$. After a period of normal column operation, a sidestream was withdrawn, isotopically equilibrated, and reinjected into the column. The performance was then measured using Raman spectroscopy for dynamic compositional analyses, which demonstrated an improvement in reboiler product purity from $55 \%$ to $99 \%$ using sidestream recycle. A second experiment was also performed using a feed composition of $H: D: T=0.204: 0.6581: 0.115$. In the current study, an additional mixture was studied which contained significantly higher concentrations of $T_{2}$, more closely resembling feeds that might be encountered in processing Tokamak exhaust gas.

\section{EXPERIMENTAL}

The first column of the Tritium Systems Test Assembly (TSTA) 4-column ISS was chosen for this study, as for the previous study, because it has 83 theoretical stages, 3 alternative feed-injection points, and seven sample withdrawal locations. The feed stream was injected into the 29th stage (counted from the reboiler). A sidestream was extracted via a metal-bellows pump from the 9th stage, equilibrated, and combined with the main feed for re-injection into the column. The nominal external feed composition to the first column was $\mathrm{H}: \mathrm{D}: \mathrm{T}=0.069: 0.301: 0.630$ at a rate of $1319 \mathrm{sccm}$ during the sidestream recycle experiments. The column pressure was 808 Torr; the reflux ratio was 120; condenser and reboiler flow rates were 415 and $904 \mathrm{sccm}$, respectively; recycle flow rate was $4112 \mathrm{sccm}$; and the reboiler contained $45 \mathrm{ml}$ of liquid. The reboiler composition was monitored every 3 minutes over a period of 8 hours using on-line Raman spectroscopy of the hydrogen isotope rotational lines. A comparison of the experimental observations of reboiler composition with computer simulations is shown in Figure 1. Note that the experimental steady state value of tritium purity agreed well with the predicted value from computer simulations, and demonstrated an improvement in tritium purity from $80 \%$ to $95 \%$ using sidestream recycle. While the observed dynamics initially agreed with the simulation, the column achieved its high steady-state purity within about 3 hours, substantially faster than predicted by the simulation. This may be due to limitations of the present Raman spectroscopic system which does not permit simultaneous observation of more than one sample tap. 
Further analysis of the data presented in the previous paper[1] results in a value of the liquid holdup on the packing of $10.1 \%$ of the superficial volume for DT and $\mathrm{T}_{2}$ mixtures. This compares favorably with the previously measured value of $9.5 \%$ for $\mathrm{H}_{2}$ and $\mathrm{D}_{2}[2-3]$.

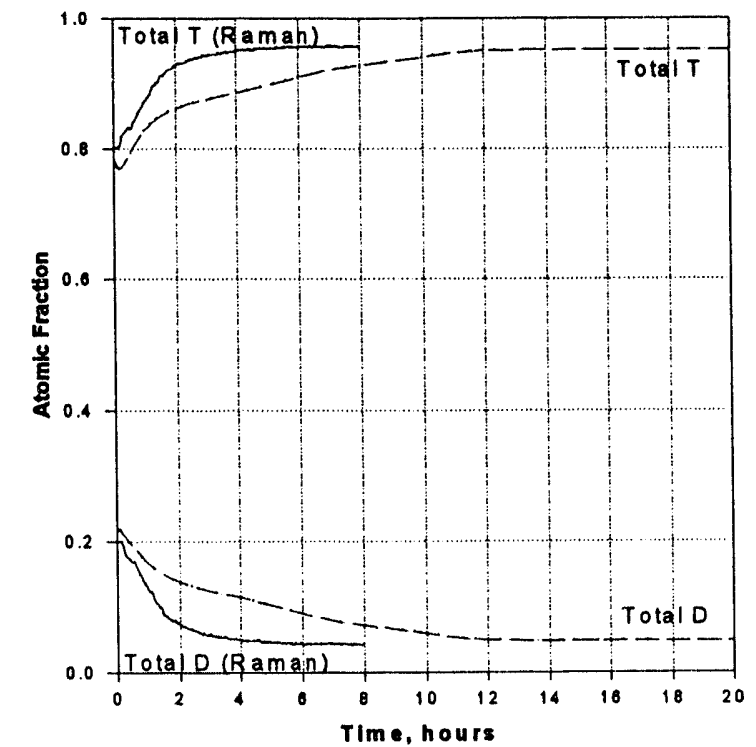

Fig. 1 Comparison of observed (solid lines) and calculated (dashed lines) reboiler composition following initiation of sidestream recycle.

\section{DESIGN}

In designing a system of columns for the decomposition of DT and the extraction of $T_{2}$ there are choices of either a) a two-column cascade with recycle from the second column back to the first, or b) a single column with sidestream recycle; these are shown in Figure 2. The high-tritium column designed by Sulzer Brothers for recovery of tritium at the ILL reactor is an example of case ' $a$ ' [4]. Even though the columns appears to be a single column, they are actually two columns arranged vertically with the condenser of the lower column acting as the reboiler of the upper column; a passive isotopic equilibrator is included in the interconnection between columns. The Los Alamos distillation dynamic computer simulation code has been used to determine optimal conditions for both choices of column configuration assuming a feed of $100 \mathrm{moles} / \mathrm{hr}$ of $\mathrm{H}: \mathrm{D}: \mathrm{T}=0.01: 0.495: 0.495$ similar to what might be expected from the processing of the high-tritium fuel stream from a Tokamak fusion energy device. In this case the DT molecule must be decomposed as given by the equilibrium reaction:

$$
2 D T \Leftrightarrow D_{2}+T_{2}
$$

A second set of conditions was determined for a feed stream of $H: D: T=0.495: 0.01: 0.495$ such as might be encountered in blanket or waste processing. In this case it is the HT molecule which is to be removed according to:

$$
2 H T \Leftrightarrow H_{2}+T_{2} \text {. }
$$

Operating conditions are summarized in Table I. Figure 3 shows the results of changing the sidestream location for the single-column sidestream recycle case. In a multicomponent distillation one or more of the components (such as HT or DT) may reach a maximum concentration at some intermediate stage. The location of such a maximum is often very dependent on the ratio of top to bottom flows. As the reboiler withdrawal fraction changes the maximum will move up or down the column, and column inventory may show large changes. The optimal location of a sidestream stage is near this maximum; however the extraction of the sidestream will, in turn, alter the column concentration profiles. Once the optimal location for sidestream withdrawal is determined one can then decide the optimal location for re-injection of the equilibrated recycle stream. Such a determination is

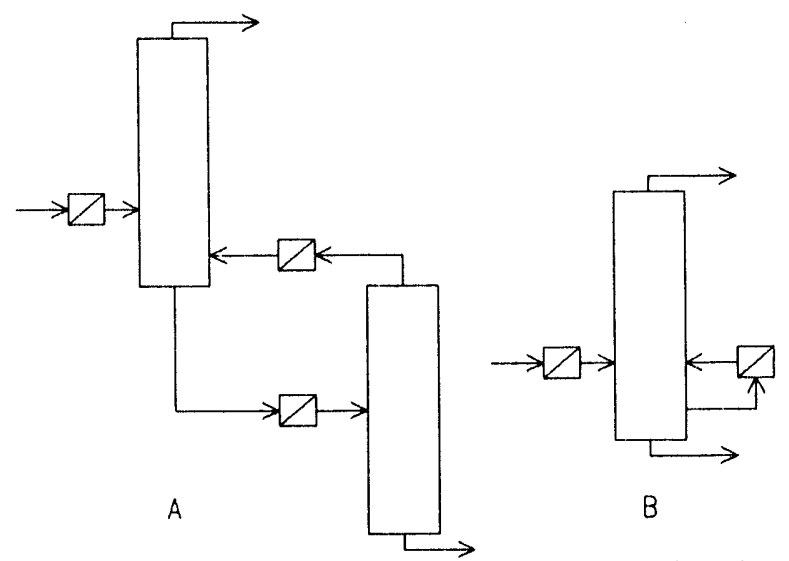

Fig. 2 One- and two-column configurations showing distillation columns and equilibrators

Table I

Column Parameters

\begin{tabular}{l|rr|}
\hline Parameter & \multicolumn{2}{|c|}{ Diatomic Species } \\
\cline { 2 - 3 } & HT & DT \\
\hline Stages & 83 & 83 \\
Pressure & 760 & 760 \\
Reflux ratio & 20 & 20 \\
Top fraction & 0.51 & 0.49 \\
Bottom fraction & 0.49 & 0.51 \\
Sidestream rate, & $6: 1$ & $6: 1$ \\
$\quad$ relative to feed & & \\
Optimal withdrawal stage & 10 & 50
\end{tabular}

shown in Figure 4 from which it is seen that the optimal return location is generally one or two stages below the sidestream extraction stage. Two other important parameters in the overall column design are the reflux ratio and the sidestream flowrate relative to the main feed rate. These are shown in Figures 5 and 6. It can be seen that a return flowrate factor of at least 3 is necessary for effective application of sidestream recycle. The effect of 
return stream location in the two-column configuration is shown in Figure 7; the effect of sidestream location on tritium holdup is shown in Figure 8. These figures make clear the desirability of being able to adjust sidestream and recycle taps. The percentage effect on column inventory is much stronger in the sidestream recycle case.

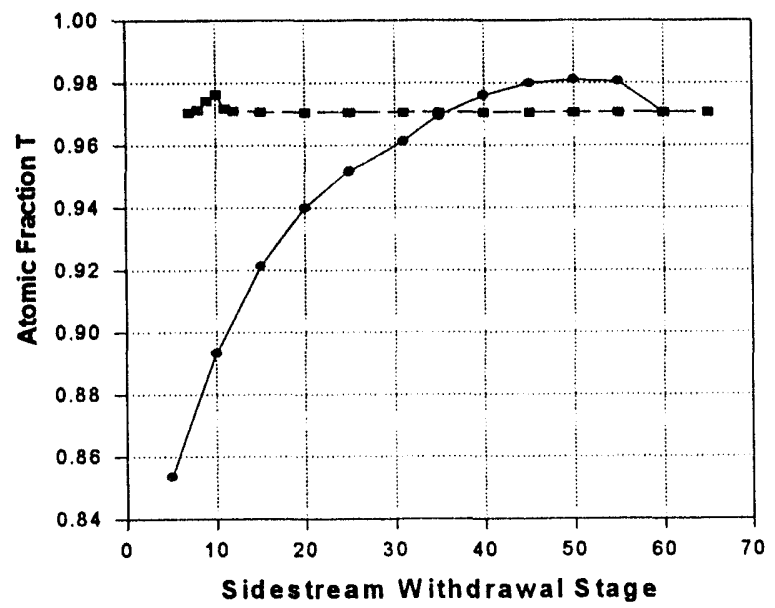

Fig. 3 Effect of location for sidestream withdrawal on reboiler purity - HT, - DT.

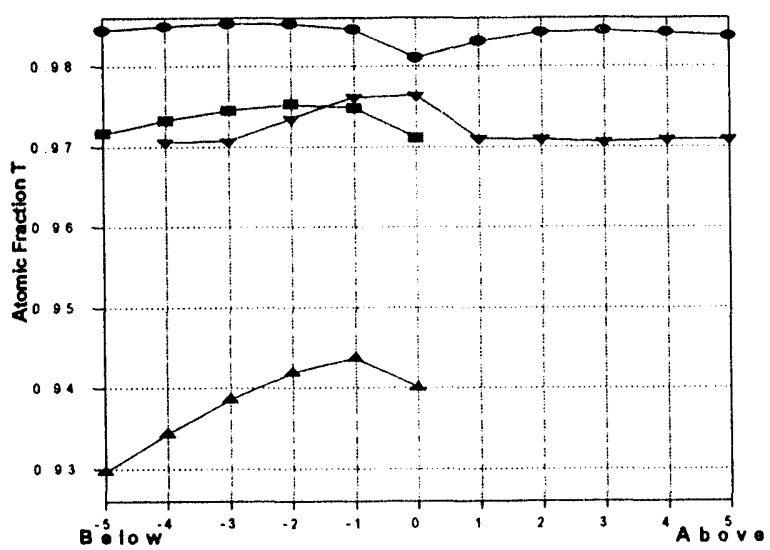

Injection stage Relative to Withdrawal stage

Fig. 4 Effect of stage offset in re-injection of equilibrated sidestream on

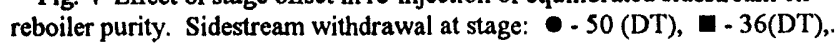
$\Delta-20(\mathrm{DT}), \nabla-10(\mathrm{HT})$

It is always simpler to control a single column. Each additional column in a cascade adds additional complication, especially if there are recycle streams to a previous column. The choice of a one- or two-column system is often a quite subjective decision. A two-column system offers greater flexibility in its ability to accommodate variations in the feed composition. To achieve minimum inventory the one-column system is preferable. A method of accommodating variations in feed composition is to provide a series of withdrawal/reinjection taps which could be selected on-line to provide optimal column operation.

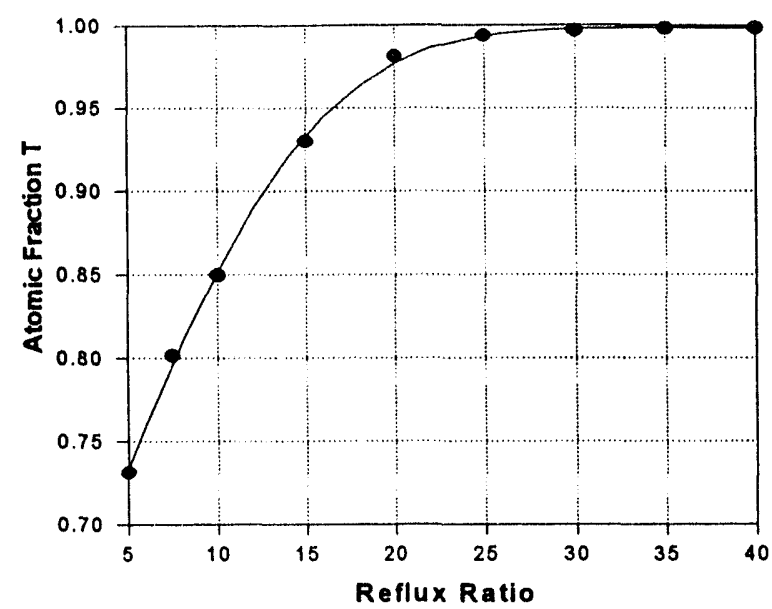

Fig. 5 Effect of reflux ratio on reboiler purity for the DT case.

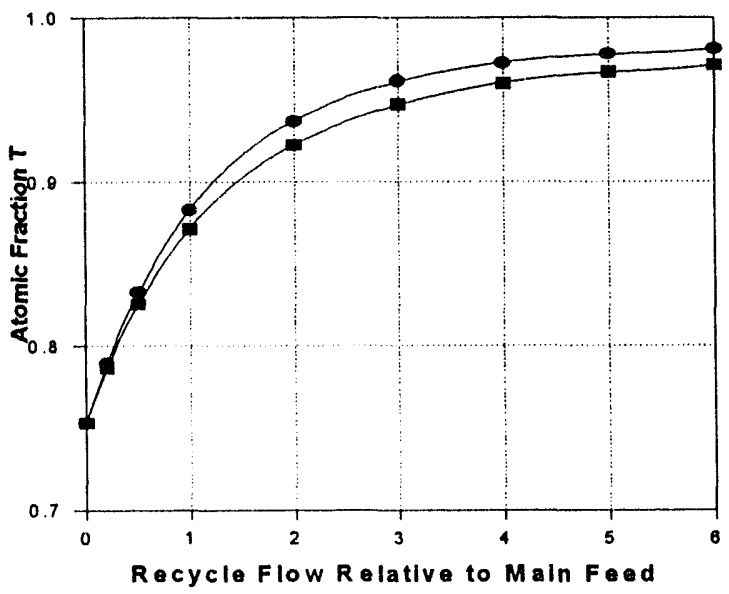

Fig. 6 Effect of sidestream flow rate relative to main feed flow rate for the DT case. Sidestream at stage: $\bullet$ - 50, $\mathbf{\square}-36$.

The important parameters are summarized in Table II. From the total $\mathrm{T}_{2}$ holdup it can be seen that a two-column system will have a holdup of 69.9 moles as compared with 46.9 moles for a single column with sidestream recycle, corresponding to at least 1.5 times higher tritium inventory.

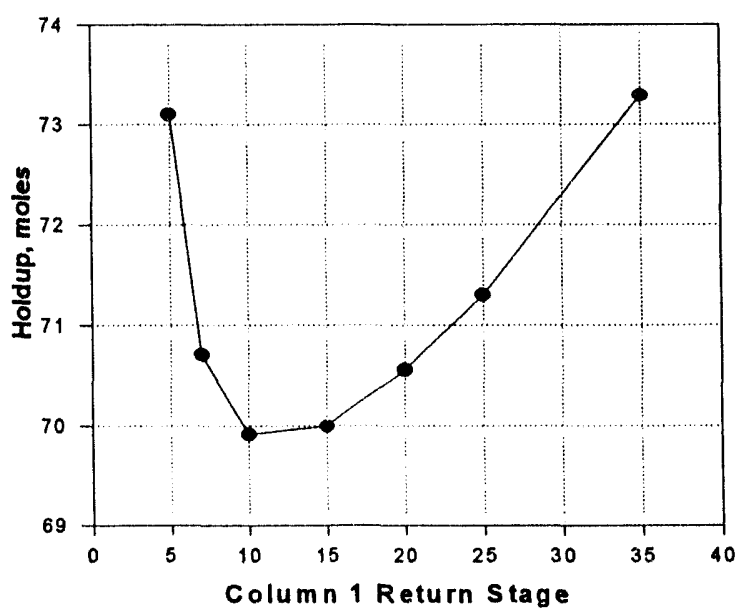

Fig. 7 Effect of return stage on holdup for two columns with DT feed 


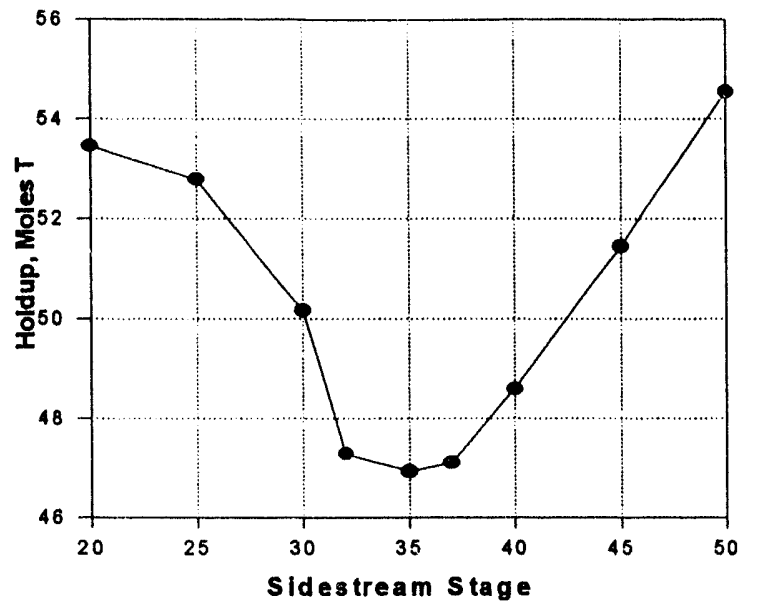

Fig. 8 Effect of sidestream stage on holdup for single column with DT feed

Table II

Column Parameters for Holdup Comparison

\begin{tabular}{l|r|r|r|}
\hline Parameter & $\begin{array}{r}\text { Two } \\
\text { Column }\end{array}$ & $\begin{array}{r}\text { Two } \\
\text { Column }\end{array}$ & $\begin{array}{r}\text { Single } \\
\text { Column }\end{array}$ \\
\cline { 2 - 4 } & $\# 1$ & $\# 2$ & \\
\hline Stages & 83 & 65 & 83 \\
Pressure, Torr & 760 & 760 & 760 \\
Diameter, cm & 8.5 & 8.1 & 9.5 \\
Reflux ratio & 20 & 5 & 25 \\
Top fraction & 0.495 & & 0.495 \\
Bottom fraction & & 0.505 & 0.505 \\
Reboiler power, Watts & 235 & 163 & 317 \\
Feed stage & 29 & 45 & 29 \\
Feed Rate, mole/h & 100 & 200.5 & 100 \\
Sidestream stage & & & 35 \\
Recycle stage & 10 & & 33 \\
Recycle rate, mole/h & & 150 & 600 \\
& & & \\
Fraction T in distillate & $7.7 \times 10^{-3}$ & & $7.60 \times 10^{-3}$ \\
Fraction T in reboiler & & 0.9708 & 0.9726 \\
Reboiler holdup, moles & 0.2 & .0 .2 & 0.2 \\
Total holdup: moles H2 & 0.34 & 0 & 0.33 \\
Total holdup: moles D2 & 85.4 & 22.9 & 78.3 \\
Total holdup: moles T2 & 16.8 & 53.1 & 46.9
\end{tabular}

As mentioned above, various tradeoffs must be weighed in reaching the final design of a system of columns to perform a specified separation. These tradeoffs are summarized in Table III.

Table III

Comparison of one- and two-column systems

\begin{tabular}{|lrr|}
\hline Parameter & $\begin{array}{r}\text { Two } \\
\text { Column }\end{array}$ & $\begin{array}{r}\text { Single } \\
\text { Column }\end{array}$ \\
\hline Number of stages & more & less \\
Reboiler power & more & less \\
Holdup & more & less \\
Ease of control & complicated & simple \\
Flexibility & more & less
\end{tabular}

\section{CONCLUSIONS}

Further verification of the application of the sidestream recycle technique to hydrogen isotope separation has been carried out. Traditionally it has been necessary to make use of a 2-column cascade to extract a pure $T_{2}$ product from an $D_{2}-D T-T_{2}$ mixture. Each of the two columns would have a significant inventory of tritium. The use of the sidestream recycle configuration permits the elimination of one distillation column and can result in a tritium inventory reduction by a factor of 1.5 . Additionally, control of a single column is simpler that a two-column cascade.

\section{ACKNOWLEDGMENT}

This work was supported by the U.S. DOE, Office of Fusion Energy and the Japan Atomic Energy Research Institute.

\section{REFERENCES}

[1] R. H. Sherman, D. J. Taylor, J. W. Barnes, T. Yamanishi, M. Enoeda, S. Konishi, and K. Okuno, "Application of Sidestream Recycle to the Separation of Hydrogen Isotopes by Cryogenic Distillation," 15th IEEE/NPSS Symposium on Fusion Engineering," Vol. 1, pp. 77-79, October 1993.

[2] R. H. Sherman, J. R. Bartlit, and D. K. Veirs, "Experimental Results from Hydrogen/Deuterium Distillations at the Tritium Systems Test Assembly," Fusion Technology, 6, 625628(1984).

[3] T. Yamanishi, H. Yoshida, S. Hirata, T. Naito, Y. Naruse, R. H. Sherman, J. R. Bartlit, K. M. Gruetzmacher. and J. L. Anderson, "Single and Two-Column H-D-T Distillation Experiments at TSTA," Fusion Technology, 14, 489-494(1988).

[4] M. Damiani, R. Gétraud, and A. Senn, "Tritium and Hydrogen Extraction Plants for Atomic Power Reactors," Sulzer Technical Review, Special Number 'Nuclex 72' pp 41-45. 

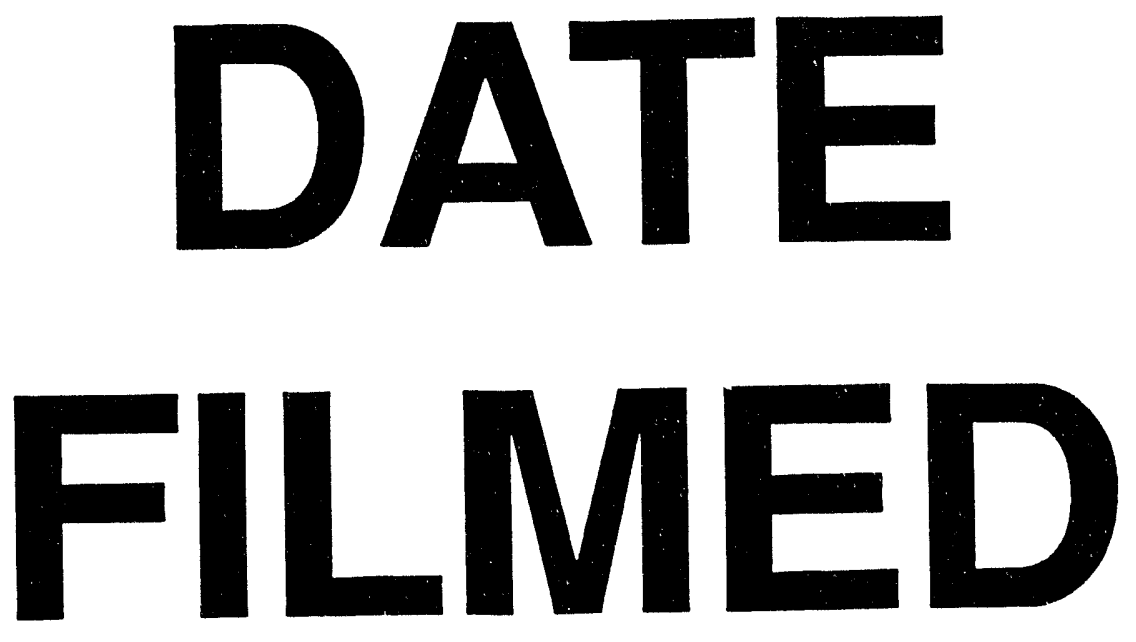

$8 / 11 / 94$
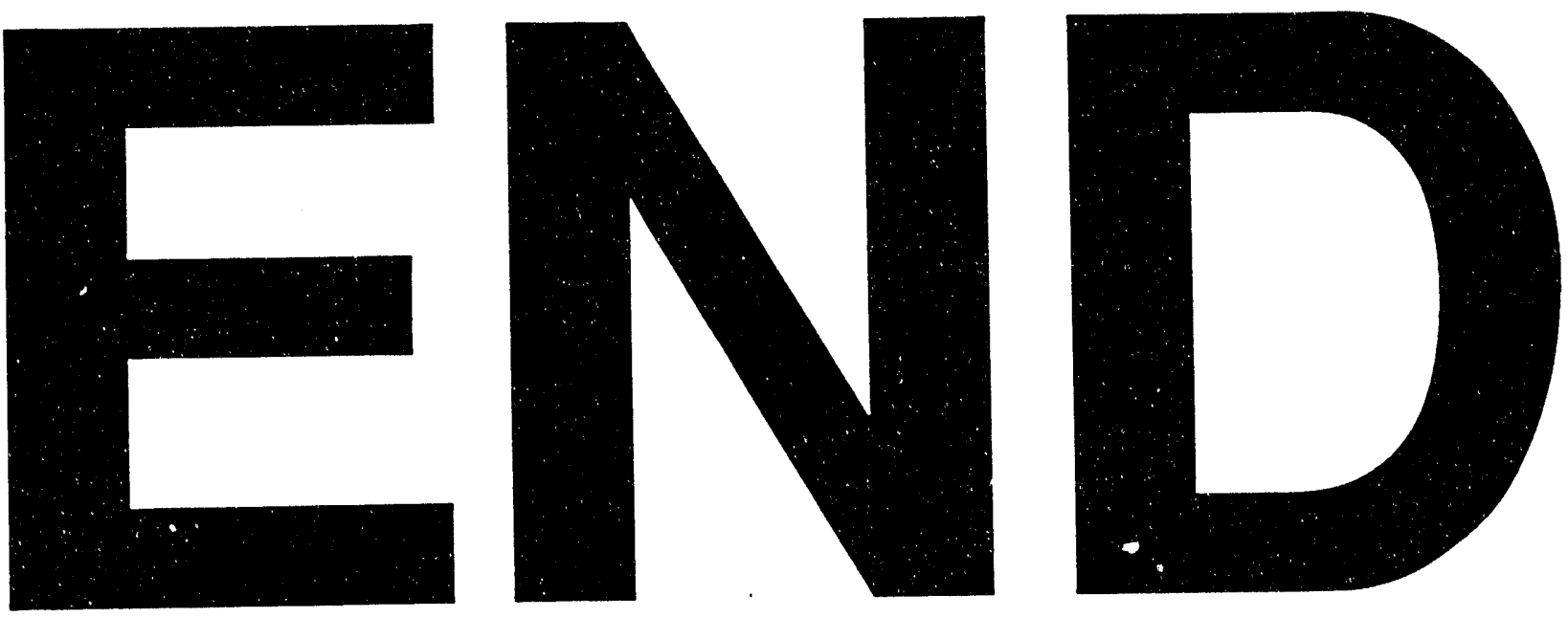
